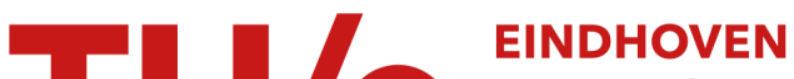 \\ UNIVERSITY OF \\ TECHNOLOGY
}

\section{Thermal expansion of Ti-substituted barium hexaferrite}

Citation for published version (APA):

Hernandez-Gomez, P., Francisco, de, C., Brabers, V. A. M., \& Dalderop, J. H. J. (2000). Thermal expansion of Ti-substituted barium hexaferrite. Journal of Applied Physics, 87(7), 3576-3578. https://doi.org/10.1063/1.372384

DOI:

10.1063/1.372384

Document status and date:

Published: 01/01/2000

\section{Document Version:}

Publisher's PDF, also known as Version of Record (includes final page, issue and volume numbers)

\section{Please check the document version of this publication:}

- A submitted manuscript is the version of the article upon submission and before peer-review. There can be important differences between the submitted version and the official published version of record. People interested in the research are advised to contact the author for the final version of the publication, or visit the $\mathrm{DOI}$ to the publisher's website.

- The final author version and the galley proof are versions of the publication after peer review.

- The final published version features the final layout of the paper including the volume, issue and page numbers.

Link to publication

\section{General rights}

Copyright and moral rights for the publications made accessible in the public portal are retained by the authors and/or other copyright owners and it is a condition of accessing publications that users recognise and abide by the legal requirements associated with these rights.

- Users may download and print one copy of any publication from the public portal for the purpose of private study or research.

- You may not further distribute the material or use it for any profit-making activity or commercial gain

- You may freely distribute the URL identifying the publication in the public portal.

If the publication is distributed under the terms of Article $25 \mathrm{fa}$ of the Dutch Copyright Act, indicated by the "Taverne" license above, please follow below link for the End User Agreement:

www.tue.nl/taverne

\section{Take down policy}

If you believe that this document breaches copyright please contact us at:

openaccess@tue.nl

providing details and we will investigate your claim. 


\title{
Thermal expansion of Ti-substituted barium hexaferrite
}

\author{
P. Hernández-Gómez a) and C. de Francisco \\ Departamento de Electricidad y Electrónica, Universidad de Valladolid, E-47071 Valladolid, Spain
}

V. A. M. Brabers and J. H. J. Dalderop

Department of Physics, Eindhoven, The Netherlands

(Received 20 September 1999; accepted for publication 19 December 1999)

\begin{abstract}
Thermal expansion measurements in the range of $20-500{ }^{\circ} \mathrm{C}$ were carried out on both poly- and single crystalline samples of the hexagonal magnetoplumbite ferrite with composition $\mathrm{BaTiFe}_{11} \mathrm{O}_{19}$. The continuous scanning of the thermal expansion reveals the existence of a $\lambda$-type anomaly near the Curie temperature. In contrast to the usual observed anisotropic behavior for magnetoplumbite hexaferrites, the averaged thermal expansion coefficient for the $a$ direction is larger than for the $c$ direction, i.e., $12.8 \times 10^{-6}$ and $9.5 \times 10^{-6}{ }^{\circ} \mathrm{C}^{-1}$, respectively. (C) 2000 American Institute of Physics. [S0021-8979(00)00107-9]
\end{abstract}

Hexagonal ferrites $\mathrm{MFe}_{12} \mathrm{O}_{19}(\mathrm{M}=\mathrm{Ba}, \mathrm{Sr}$, or $\mathrm{Pb})$ with the magnetoplumbite structure are widely used as permanent magnet materials due to the rather good energy product-cost ratio but there is also an increasing interest in using these materials as magnetic and magneto-optic recording media, as well as in microwave devices. Up until now the magnetic properties of these materials related to permanent magnet applications have been mainly tailored by the microstructure and not by chemical substitutions.

However, chemical substitutions are more suitable for improving the performance of these materials for magnetic recording media. Recent studies on Ti-substituted $\mathrm{BaFe}_{12} \mathrm{O}_{19}$ have shown that $\mathrm{Ti}$ substitution strongly affects the magnetic properties. ${ }^{1-3}$ For instance, an enhancement of the magnetic anisotropy was found for small concentrations of $\mathrm{Ti}$ in the system $\mathrm{BaFe}_{12-x} \mathrm{Ti}_{x} \mathrm{O}_{19}(x \approx 0.2)$, whereas for higher concentrations $(\mathrm{Ti} \approx 1.0)$ the anisotropy decreases with progressive Ti substitution.

In a number of cases, the hexagonal ferrites have to be grown as thin films to be used in the above mentioned applications. The coefficient of thermal expansion is an important physical parameter in the growth of films, in order to ensure the suitability of the substrate employed. ${ }^{4}$ In this paper we report the results of the continuous scanning of the thermal expansion on Ti-substituted barium ferrite with composition $\mathrm{BaFe}_{11} \mathrm{TiO}_{19}$. Keeping in mind the anisotropy of the hexagonal structure, measurements on single crystalline specimens in both parallel and perpendicular directions to the $c$ axis were performed, as well as on a polycrystalline sample.

Polycrystalline bars were prepared by a ceramic technique which includes several prefiring and ball milling stages and finally isostatically pressing followed by sintering at $1350^{\circ} \mathrm{C}$ in $10^{-3}$ atm oxygen. $\mathrm{X}$-ray diffraction measurements confirm that the material is a single phase magnetoplumbite with lattice parameters $a=5.885 \pm 0.001 \AA$ and $c=23.290 \pm 0.005 \AA$.

a) Author to whom correspondence should be addressed; electronic mail: pabloher@ee.uva.es
Single crystals of $\mathrm{BaFe}_{11} \mathrm{TiO}_{19}$ were prepared by a recrystallization process of the polycrystalline bars based on a floating zone technique using an arc-image furnace. ${ }^{5}$ In contrast to pure $\mathrm{BaFe}_{12} \mathrm{O}_{19}$, the ferrite $\mathrm{BaFe}_{11} \mathrm{TiO}_{19}$ melts congruently, which enables us to grow large single crystals without additional flux in the molten zone. ${ }^{1}$ The lattice parameters of the single crystals turned out to be within experimental error equal to the polycrystalline parameters. From the as-grown single crystalline ingots, rectangular bars, $2 \times 2 \times 20$ (resp. 7) $\mathrm{mm}$, were cut along the $a$ (resp. c) directions, and used as samples for the thermal expansion measurements.

Thermal expansion measurements have been carried out on both poly- as well as on single crystalline samples in the temperature range of $20-500^{\circ} \mathrm{C}$ using a dilatometer based on a differential transformer as the displacement recording system. In order to prevent oxidation of the samples and hence avoid changes in the defect content, the measuring process was performed in an inert $\mathrm{N}_{2}$ atmosphere. For each sample the measurement has been carried out several times in order to ensure the reliability of the results.

In Fig. 1 the thermal expansion traces determined in the $c$ and $a$ directions as well as the results for the polycrystalline samples are plotted. As can be seen, the thermal expansion is not linear, which is primarily caused by the magnetic contribution to the thermal expansion. In Fig. 2, the temperature dependence of the thermal expansion coefficients is shown, which clearly reveals the $\lambda$ anomaly, with a maximum value of the expansion coefficient near the Curie temperature $\left(325^{\circ} \mathrm{C}\right)$. The thermal expansion coefficients were calculated using the approach given in Ref. 6 from the derivation of the experimental curves of Fig. 1.

Similar anomalous temperature dependences of the thermal expansion coefficients were already reported for unsubstituted isotropic polycrystalline $\mathrm{BaFe}_{12} \mathrm{O}_{19}$ (Ref. 7) and for magnetically oriented polycrystalline $\mathrm{SrFe}_{12} \mathrm{O}_{19}$ in the direction of orientation and perpendicular to it. ${ }^{8}$ The measurements on the oriented $\mathrm{SrFe}_{12} \mathrm{O}_{19}$ are also indicative of the anisotropic thermal expansion in the $a$ and $c$ directions, with a larger expansion in the $c$ direction of about 20\%. Compa- 


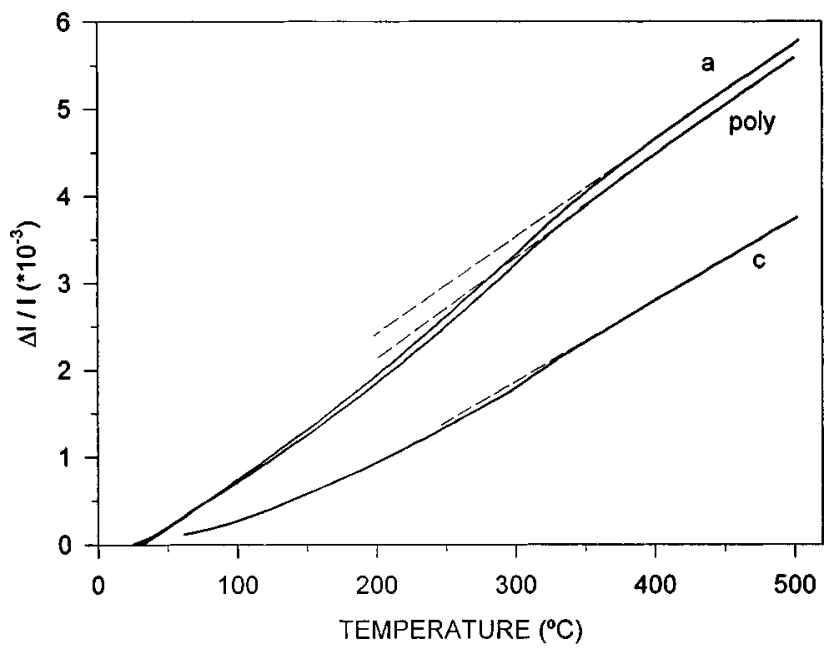

FIG. 1. Thermal expansion traces for $\mathrm{BaFe}_{11} \mathrm{TiO}_{19}$ in the $a$ and $c$ directions as well as for an isotropic polycrystalline sample.

rable results concerning the anisotropy and the $\lambda$ anomaly were reported for the temperature dependence of the lattice parameters of unsubstituted $\mathrm{BaFe}_{12} \mathrm{O}_{19}$ with a slightly larger expansion in the $c$ direction of about $4 \%$ over a total temperature range of $20-600^{\circ} \mathrm{C} .{ }^{9}$

More recently, ${ }^{4}$ a larger anisotropy of about $22 \%$ was reported for $\mathrm{BaFe}_{12} \mathrm{O}_{19}$, but from the experimental data no temperature dependence of expansion coefficient could be revealed, which must be due to the resolution of the experimental technique used by these authors. The thermal expansion coefficients along the $a$ and $c$ directions were reported to be $10.0 \times 10^{-6}\left({ }^{\circ} \mathrm{C}^{-1}\right)$, and $12.2 \times 10^{-6}$, respectively. ${ }^{4}$ In contrast with the available data in literature on $\mathrm{M}$ hexaferrites, ${ }^{4,7-9}$ our results for $\mathrm{BaFe}_{11} \mathrm{TiO}_{19}$ indicate just a lower thermal expansion in the $c$ direction. For the thermal expansion coefficient averaged over the temperature range of $20-500^{\circ} \mathrm{C}$ values of $12.8 \times 10^{-6}$ and $9.5 \times 10^{-6}$ were found for the $a$ and $c$ direction, respectively. Compared with pure $\mathrm{BaFe}_{12} \mathrm{O}_{19}$, the composition of our investigated hexaferrite is not so different that one could expect a drastic change in the lattice thermal expansion. Indeed, the data for $\mathrm{BaFe}_{12} \mathrm{O}_{19}$ above the Curie temperature given in Ref. 9 may be considered as the lattice thermal expansion, which show that the lattice thermal expansion contribution in the $c$ direction is lower than in the $a$ direction in agreement with our findings. In addition, the consistency of our results is supported by the value obtained for the polycrystalline sample. For a random crystallite orientation in this sample, the longitudinal expansion measured involves the contribution of a third of crystallites whose $c$ axis is aligned with the measuring direction and two thirds perpendicular to it. The averaged thermal expansion coefficient of $12.0 \times 10^{-6}{ }^{\circ} \mathrm{C}^{-1}$ found for the polycrystalline sample agrees rather well with this model.

The discrepancies in the thermal expansion below the Curie temperature between the present and literature data must then be due to the magnetic contribution to the thermal expansion. The substitution of $\mathrm{Fe}^{3+}$ by $\mathrm{Ti}^{4+}$ means also that an equivalent amount of $\mathrm{Fe}^{2+}$ ions are introduced in the lattice. According to Ref. 10 the $\mathrm{Ti}^{4+}$ ions occupy preferen-

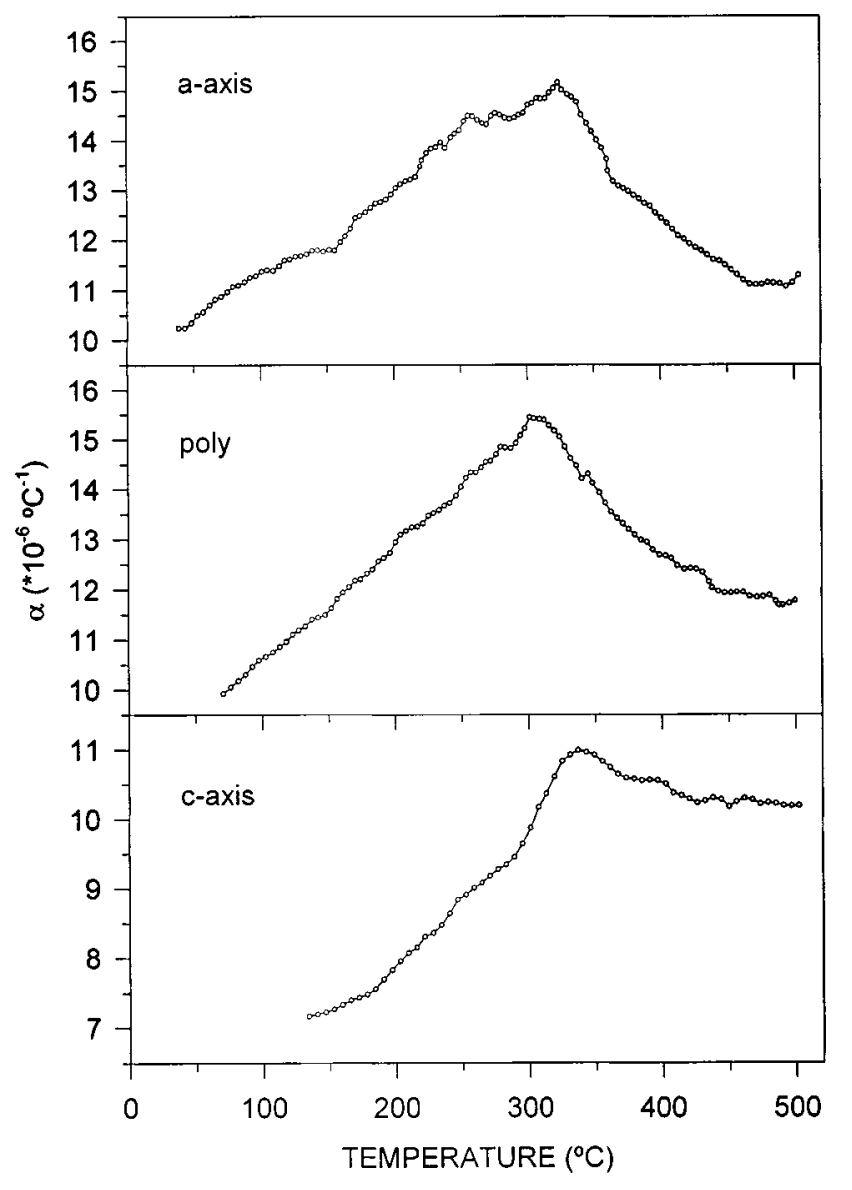

FIG. 2. The temperature dependence of the thermal expansion coefficient of $\mathrm{BaFe}_{11} \mathrm{TiO}_{19}$ along the $a$ and $c$ axis and for an isotropic polycrystalline sample.

tially the $4 f_{2}$ sites of the magnetoplumbite structure and the $\mathrm{Fe}^{2+}$ will probably be located as nearest neighbors in the same sublattice. Substitution of $\mathrm{Fe}^{2+}-\mathrm{Ti}^{4+}$ in the spinel compound $\mathrm{Fe}_{3} \mathrm{O}_{4}$ shows that strong magnetoelastic effects ${ }^{11}$ are related to this substitution in oxides, and similar effects might be expected for the hexaferrites.

A second mechanism for the relatively low thermal expansion in the $c$ direction might be the thermal excitation of the sixth $3 d$ electron of an $\mathrm{Fe}^{2+}$ ion neighboring $\mathrm{Ti}^{4+}$ to the next nearest $\mathrm{Fe}^{3+}$ ion. Substitution of $\mathrm{Ti}$ in $\mathrm{BaFe}_{12} \mathrm{O}_{19}$ results in an increase of the $c$-lattice parameter, ${ }^{1}$ in spite of the smaller $\mathrm{Ti}^{4+}$ radius compared with $\mathrm{Fe}^{3+}$. This means that the increase of the $c$ parameter is due to the $\mathrm{Fe}^{2+}$ sites, neighboring the $\mathrm{Ti}^{4+}$. Because these $4 f_{2}$ sites are smaller than other iron sites in the structure, an electron transfer to these other sites would result in a smaller thermal expansion.

From this study, it is now evident that the thermal expansion coefficient of M-type hexaferrites below the Curie temperature is temperature dependent as well as dependent on the chemical substitution. For magneto-optical applications specific substitutions are desired to tailor the magnetic properties. Because of these substitutions the thermal expansion is also affected. For thin film applications it is required that the thermal expansion of the specific compositions must be determined separately in order to choose a suitable substrate to minimize the thermal expansion mismatch between 
film and substrate. The thermal expansion data for the pure $\mathrm{M}$ ferrites ${ }^{4}$ are not representative for the magneto-optical materials.

${ }^{1}$ V. A. M. Brabers, A. A. E. Stevens, J. H. J. Dalderop, and Z. Šimša, J. Magn. Magn. Mater. 196-197, 312 (1999).

${ }^{2}$ Y. Kawai, V. A. M. Brabers, Z. Šimša, and J. H. J. Dalderop, J. Magn. Magn. Mater. 196-197, 309 (1999).

${ }^{3}$ Z. Simša, R. Gerber, V. Lewis, and V. A. M. Brabers, J. Phys. IV 7, C1-197 (1997).

${ }^{4}$ P. C. Dorsey, S. B. Qadri, J. L. Feldman, J. S. Horwitz, P. Lubitz, D. B. Chrisey, and J. B. Ings, J. Appl. Phys. 79, 3517 (1996).
${ }^{5}$ V. A. M. Brabers, T. E. Whall, and P. S. A. Knapen, J. Cryst. Growth 69, 101 (1984).

${ }^{6}$ R. S. Krishnan, R. Srinivasan, and S. Devanarayanan, Thermal Expansion of Crystals (Pergamon, New York, 1979), p. 3.

${ }^{7}$ W. R. Buesem and A. Dorf, Proceedings of 13th Annual Meeting, Metal Powder Association (Chicago, IL, 1957), Vol. II, p. 196.

${ }^{8}$ C. A. M. van den Broek and A. L. Stuyts, Philips Tech. Rev. 37, 157 (1977).

${ }^{9}$ H. Kojima, Ferromagnetic Materials, edited by E. P. Wohlfarth (NorthHolland, Amsterdam, 1982), Vol. 3, p. 363.

${ }^{10}$ F. K. Lotgering, J. Phys. Chem. Solids 35, 189 (1974).

${ }^{11}$ J. Klerk and V. A. M. Brabers, J. Phys. (France) 38, C1-187 (1977). 